\title{
Assessing the Approaches to Learning of Twinning Programme Students in Malaysia
}

\section{PAULINE GOH SWEE CHOO}

Universiti Tunku Abdul Rahman

\begin{abstract}
The study set out to examine the psychometric properties of the scores obtained on the modified 20-item Revised Two Factor Study Process Questionnaire (R-SPQ-2F). The study also investigated the relationship between scores on the R-SPQ-2F and students' learning-related outcomes. In addition, it also examined for any relationships among student's background variables of gender, choice of academic discipline, age, English language competency, approaches to learning, and learning-related outcomes. Data based on responses of 368 Malaysian students undertaking the twinning mode of study showed the modified $\mathrm{R}-S P Q-2 \mathrm{~F}$ to be reliable and factorially valid. The findings also found deep approaches to learning were positively related to students' learning-related outcomes, while surface approaches to learning were negatively associated. Students' background characteristics such as choice of academic discipline and English language competency, and approaches to learning were good predictors of students' learning-related outcomes.
\end{abstract}

\section{INTRODUCTION}

The enactment of the 1996 Private Higher Education Act in Malaysia saw a rapid expansion of Private Higher Educational Institutions (PHEI), and an increase of students enrolled in PHEI. The Act was enacted because the Ministry of Education wanted to democratise education and provide equal opportunities for more students to achieve a degree, but at the same time provide meaningful learning in PHEI. Many PHEI have established linkages called 'Twinning Degree Programme' with curriculum imported from overseas western universities, of which Australia and the United Kingdom are well represented. Typical twinning arrangements are ' $1+2$ ' (one year in local PHEI and two years in overseas partner university), ' $2+1$ ' or ' $2+2$ ' year arrangements. In ' $3+0$ ', students are allowed to complete the foreign degree entirely at the local PHEI. 
In 1999 the former Minister of Education, Datuk Seri Najib Tun Razak suggested that PHEI would be rated as a means for the public to gauge the performance of a private institution. This is in line with the call to make Malaysia the 'centre of educational excellence'. PHEI are now required to maintain and enhance the quality of effective learning within their management and organisation systems.

Concerns about quality of student learning in tertiary education are not a new phenomenon. In recent years, there have been significant efforts by researchers and educators towards addressing this issue and the expanding field on student learning research has produced many suggestions of what we should be doing to encourage quality learning. Although much of the research originated from the west, there has also been research carried out, of late, on the learning processes of Asian students studying in western universities, especially from the student approaches to learning (SAL) position. Student approaches to learning was derived from an experiment by Marton and Säljö (1976) to examine students' experience of a particular learning situation. They demonstrated that how each student goes about their learning will be different, and so will their perceptions of the way they should handle the learning and hence differences in learning-related outcomes.

Much of the student approaches to learning research has emanated from Australia and Britain (Harris, 1997; Matthews, 2003; Ramburuth, 2000; Smith, 2001; Volet \& Ang, 1998; Volet, Renshaw, \& Tietzel, 1994). While the research into students' approaches to learning can be assumed to be pertinent to students studying in western universities, there is less confidence of the pertinence to Asian students' learning in their home country. Research that attempts to repeat the investigations in students' home countries tend to be limited to looking at students undertaking their own institution's curriculum in their national language (Kember \& Leung, 1998a; Kember, Charlesworth, Davies, Mckay, \& Stott, 1997; Leung \& Kember, 2003; Tan, 1990; Wan Ali, 2000; Watkins \& Ismail, 1994). Therefore, while the research has contributed to the growing knowledge of Asian students' approaches to learning and learning outcomes, the extent to which Twinning Programme students are able to accommodate different approaches to learning within an imported Australian and British curriculum, completed entirely in the English Language, in their home country have not been examined. One such country is Malaysia where PHEI students come from different cultural traditions and different 
educational systems and practices. Matthews (2003) and Volet and Kee (1993) indicated that issues relating to students' learning in culturally different contexts have received very little attention. The present investigation is therefore unique in reporting the approaches to learning of Malaysian students undertaking the twinning programmes.

\section{APPROACHES TO LEARNING}

The phenomenographic work conducted by Marton and Säljö (1976) identified two levels of processing: deep and surface. A deep approach entails looking for meaning in the matter being studied and relating it to other experiences and ideas with a critical approach. In contrast, a surface approach refers to the intention to reproduce the learning material, the surface learner have an over reliance on rote-learning and memorisation in isolation from other ideas. It has been demonstrated that a deep level approach tends to lead to a qualitatively superior learning outcome (Biggs, 1993; Knight, 1995; Trigwell \& Prosser, 1991). Typically, the development of a deep approach is consistent with the avowed aims of tertiary education. Students in higher education are expected to show a deeper level of critical thinking, and more ability to engage in self-directed learning than less advanced students.

However, it has been argued that phenomenography was not able to provide a tangible empirical evidence of student approaches to learning. It lacks methodological and theoretical consistencies (Richardson, 1994; Meyer, 1998). As a result, the phenomenographic work by Marton and Säljö (1976) has been extended by researchers using a range of methods to arrive at interpretive methods of modelling student learning. Quantitative methods using psychometric techniques have been adopted to develop questionnaires that can reflect specific dimensions of students' learning approaches. Advocates of measuring students' approaches to learning see it as a means to assist academics monitor and improve effectiveness of their own teaching. In addition, it gives an opportunity to assess and identify students who are at risk through the use of ineffective study strategies and provide an avenue to evaluate the quality of student learning (Richardson, 1990; Tait \& Entwistle, 1996; Biggs, 1993, 2001). 
Research efforts addressing students' approaches to learning can be readily framed within Biggs (1989) 3P model, which conceptualises that the process of student learning as an interrelationship between the personal and background characteristics of students, the situational constrains, their approaches to learning and the outcomes of that learning. The model works in equilibrium but changes to any component affect the whole system. Therefore, a change in the teachinglearning context may result in a change in approach to learning and ultimately to the learning-related outcomes itself.

Objectives of tertiary education, therefore, is to create a teaching-learning environment that encourages students to develop deep approaches to learning, encouraging them to develop a conceptual understanding of their course material, and subsequently result in higher quality learning-related outcomes. According to Biggs (1993), Trigwell and Prosser (1991), and Zakaria (2000) quality learning-related outcomes encompasses both academic performance as well as the development of higher order skills such as the ability to think critically and analytically.

\section{THE STUDY PROCESS QUESTIONNAIRE}

The Study Process Questionnaire (SPQ) was developed within the framework of the 3P model and is used to assess the extent to which students use deep or surface approaches (Biggs, 1987). To these two approaches, Biggs (1987) added an achieving approach where the students' motivation is to employ strategies that can lead them to obtain the best possible marks. In its most commonly used version, the SPQ measuring surface-deep-achieving approaches contains 42 five-point items and is divided into six subscales. The subscales are made up of a strategy and motive component: surface motive, surface strategy, deep motive, deep strategy, achieving motive and achieving strategy.

Since identifying the approaches students use in learning is of great practical educational importance in both improving student learning and improving the curriculum, the SPQ has been widely applied in cross-cultural researches (Hattie \& Watkins, 1981; O’Neil \& Child, 1984; Watkins \& Regmi, 1990; Watkins \& Akande, 1992; Zhang, 2000; Snelgrove \& Slater, 2003). All these studies reported on the reliability of the six subscales of the SPQ and their factor structure. 
However, the results of the factor analyses upon students' responses to the 42 items suggest doubt about the existence of a separate 'achieving' approach. The results indicate that the deep and surface approaches are conceptually sound, but there are some conceptual overlaps between the deep and achieving approaches. Kember and Leung (1998) argue that approaches to learning would be better represented by a two-factor solution than the three-factor solution as originally proposed. Kember and Leung consider that the achieving approach was an additional dimension of the surface approach rather than a separate measurement.

\section{THE REVISED TWO-FACTOR STUDY PROCESS QUESTIONNAIRE}

The SPQ has recently undergone extensive revision, with a 20item two-factor solution version developed by Biggs, Kember and Leung (2001) and named the Revised Two Factor Study Process Questionnaire (R-SPQ-2F). Biggs et al. (2001) suggest that it was timely to make adjustments to the SPQ as 'the student population is more heterogeneous than it was, and on the other hand, with the modularisation of teaching units, students' courses of study are now more programme-based than faculty-based' (p. 134). They maintain that the SPQ has an even greater role to play than before in gauging student learning in the light of changing teaching contexts, accountability, and concerns with quality assurance. The revised and shortened R-SPQ-2F has great potential in providing quick and useful data in a number of areas such as teaching quality and curriculum innovations.

Considering that the R-SPQ- $2 \mathrm{~F}$ is a useful and an inexpensive tool to gauge the quality of student learning in a Malaysian context, a literature search reveals a lack of evidence considering the psychometric properties of the R-SPQ-2F, and even less as it pertains to Malaysian students with its multicultural ethnicity coming from different social and educational experience. Table 1 shows the Cronbach alpha values for the R-SPQ-2F conducted by Biggs, Kember and Leung (2001) and Leung and Kember (2003) using a sample of Hong Kong students who are predominantly Chinese with traditional Chinese values. Biggs (1987) and Hui and Triandis (1985) have pointed out the need for cross-cultural psychometric investigation of any new instrument. 
Table 1. Comparison of Cronbach Alpha Values for R-SPQ-2F

\begin{tabular}{lcc}
\hline & \multicolumn{2}{c}{ SPQ } \\
\cline { 2 - 3 } Scales/subscales & Published in 2001 & Published in 2003 \\
\cline { 2 - 3 } & Alpha \\
\hline Deep Motive (DM) & 0.62 & 0.60 \\
Deep Strategy (DS) & 0.63 & 0.62 \\
Surface Motive (SM) & 0.72 & 0.72 \\
Surface Strategy (SS) & 0.57 & 0.59 \\
Deep Approach (DA) & 0.73 & not available \\
Surface Approach (SA) & 0.64 & not available \\
\hline
\end{tabular}

Note: Source: Biggs et al. (2001, p.142); Source: Leung and Kember (2003, p.65)

\section{STUDENTS' BACKGROUND CHARACTERISTICS}

\section{Gender Differences and Choice of Academic Discipline}

Studies using the SPQ did not reveal any definitive picture on gender differences. While these studies are not in direct contradiction, neither do they offer agreement on a consistent pattern of gender differences for the approaches to learning. Nevertheless, Marton (1976) cautions that students' approaches to learning is dependent upon their perceptions of the environments, the content and the demands of the learning task. It therefore follows that gender differences in approaches to learning might emerge in particular choices of academic discipline.

For example, Watkins, Regmi, and Astilla (1991), Watkins and Ismail (1994), and Watkins and Mboya (1997) find that males tend to report deeper level approaches more often than do females. In these countries, males are more likely to study science and mathematics. However, this seems to contradict findings by Watkins and Hattie (1981) and Biggs (1987) which show that male students in science courses exhibited more reproducing strategies (surface approach) compared to their female counterparts. Hayes and Richardson (1995) report that gender has little overall effect on approaches to learning, but students 
taking science courses obtained higher scores on surface approaches than those taking arts courses. Similarly, Wilson, Smart, and Watson (1996), Miller, Finley, and Mckinley (1990) find no gender differences on any of the main scales of the SPQ.

\section{Age Differences}

Previous investigations using SPQ to research the effects of age show that age is positively related to the employment of deep approaches to learning and negatively related to surface approaches (Gow \& Kember, 1990; Biggs, 1987; Harper \& Kember, 1986). Mature students tend to exhibit more desirable approaches to learning.

\section{English Language Competency}

Gow, Kember, and Chow (1991) set out to examine if English language used as a medium of instruction encouraged a predominantly rote learning approach. Although Gow et al. (1991) find that ability in the language does not generally affect the motivation of the students to adopt a surface approach, nevertheless, those students who are weaker in the language are more likely to adopt surface learning strategies. The findings suggest that although students are no more likely to rote-learn if they had limited English ability, the students might be compelled to employ surface strategies when confronted with English reading or writing assignments. This is true if the students are trying to understand the language and are more likely to memorise sections which had to be interpreted rather than see the whole reading globally and to seek understanding. Because of students' lower ability in the command of the language, students in the writing task may rely on verbatim copying rather than on original interpretation. These findings seem to contradict earlier findings by Biggs (1987) and a later study by Johnston (2001), where the two studies reveal that students who come from Asian backgrounds (English was a second language) in Australian universities reported higher on deep approach than did native English speakers. Nevertheless, Gow et al. (1991) caution that even if Asian students have a satisfactory command of the English language, they may be discouraged from employing a deep approach by the nature of the task and of the learning context. 


\begin{abstract}
AIMS
The research reported in this study was to establish the use of the $\mathrm{R}-\mathrm{SPQ}-2 \mathrm{~F}$ to tertiary twinning programme students in Malaysia. In the light of previous research, it also considered (i) students' approaches to learning and learning-related outcomes; (ii) students' background variables, approaches to learning and learning-related outcomes. Thus the three research questions motivating the study were:

1)Will the R-SPQ-2F demonstrate adequate psychometric properties when applied to Malaysian students, and in particular, tertiary twinning programme students?

2)Will a deep approach to learning be related to more positive learning-related outcomes than is a surface approach to learning?

3)Will students' background characteristics, deep approach to learning combine to have large associations with students' learning-related outcomes?
\end{abstract}

\title{
METHOD
}

\section{Student Sample, Selection and Instrument}

The population of students that the study was interested in were students undertaking the $3+0$ twinning programmes from either Australian or British universities. However, the target population was second and third year undergraduates taking degrees in business and business-related programmes, computer science, and engineering.

Business degrees and science (technology/engineering) degrees were selected as business and computing/engineering programs were the first courses to be granted approval to conduct a $3+0$ structure. It was hoped that there would be a sufficient number of students in their $2^{\text {nd }}$ and $3^{\text {rd }}$ year, compared to other more recent courses.

It was considered important that students who participated in the study were mature enough to make valid and careful judgements of their learning and studying at PHEI to ensure careful responses to the questionnaire items. Furthermore, it was 
considered necessary that students should be established in their place of learning and have formed a certain learning habit.

The PHEI that participated were selected based on their accessibility and the willingness of the Principal or the President of the PHEI to participate in the study. PHEI with $3+0$ twinning programmes in business, technology, and engineering degrees, and that indicated a willingness to participate in the research were listed, contacted by telephone, and invited to participate in the study. Eventually six colleges were chosen. The breakdown by sample, college, programme, gender and age is shown in Table 2.

Table 2. Breakdown of Sample by College, Programme, Gender, and Age

\begin{tabular}{|c|c|c|c|c|c|}
\hline \multirow[t]{2}{*}{ PHEI Colleges } & \multirow[t]{2}{*}{ 3+0 Twinning Degree } & \multicolumn{2}{|c|}{ No. of Students } & \multicolumn{2}{|c|}{ Age } \\
\hline & & Male & Female & $<=21$ & $>=22$ \\
\hline College A & B. Commerce & 24 & 56 & 46 & 34 \\
\hline College B & B. Comp. Science & 19 & 2 & 15 & 6 \\
\hline \multirow[t]{3}{*}{ College C } & B. Science & & & & \\
\hline & (Computing) & 29 & 29 & 17 & 41 \\
\hline & B. Engineering & 63 & 6 & 9 & 60 \\
\hline College D & B. Commerce & 8 & 20 & 14 & 14 \\
\hline \multirow[t]{2}{*}{ College E } & B. Science & & & & \\
\hline & (Comp. Science) & 7 & 11 & 8 & 10 \\
\hline College F & B. Business & 34 & 60 & 59 & 35 \\
\hline Total & & 184 & 184 & 168 & 200 \\
\hline
\end{tabular}

Out of the participants (368), 166 were doing Engineering and Computer Science programs, while the other 202 were in business, commerce, accounting, finance, or management programmes. They were made up of equal numbers of 184 males and 184 females. Some 168 students were 21 years of age and younger.

The approach to learning instrument used was the revised RSPQ-2F (Biggs, Kember, \& Leung, 2001). The R-SPQ-2F consists of 20 items measuring two main scales of Deep Approach (DA) and Surface Approach (SA). DA main scale has Deep Motive (DM) and Deep Strategy (DS) as subscales, while SA has Surface Motive (SM) and Surface Strategy (SS) as subscales. Each of the subscales (DM, DS, SM, and SS) contains five items. Each item within the subscales is rated 
on a five-point Likert scale: 1 ('This item is never or only rarely true of me') and 5 ('This item is always or almost always true of me'). Subscale scores are calculated by summing up the scores on the relevant items. All items are positively worded so that no recoding is necessary when scoring the questionnaire. Subscale scores range from five to 25 with higher scores indicating those who make a greater use of that approach to learning. It was necessary to make modifications to the wordings of some of the items to simplify the language and to make items more suitable for the Asian sample in Malaysia. In all the re-wording, the original word was followed as closely as possible so that the meaning of each item was preserved.

To explore students' perceived competency in the use of the English language in various learning situations, a Perceived English Language Competency Questionnaire (PELCQ) was developed - see Appendix 1. It gathered data relating to students' perceived competency in the use of English in areas of writing, reading, understanding, discussion, and in conversation. The questions used a five-point selfrating response scale ranging from a value of 5 ('Very Good'), 4 ('Enough'), 3 ('Only Just Enough'), 2 ('Uncertain'), and 1 ('Definitely Not Enough'). Students' English language competency was assessed by the combined scores from their self-reporting of their competency in using the English language in the five areas. Students were divided into high, medium, or low competency groups on the basis of their total score on the five-item scale of the PELCQ. The low competency group included $20 \%$ of the total sample, while $40.8 \%$ made up the medium competency group, with $39.1 \%$ of students in the high competency group.

\section{Learning-Related Outcomes}

The measures of learning-related outcomes consisted of (i) students' academic attainment; (ii) students' process skills; and (iii) students' course satisfaction.

Academic attainment was the end of session (course work and examination) results in each program of study. For all six PHEI, the fail mark (F) was 49\%, pass mark (P) was 50-59\% and high distinction (HD) pass was $80-100 \%$. Credit pass (CR) was 60 69 for Colleges B, C, D, E, and F, while college A was $60-74 \%$; distinction pass (DI) was 70-79\% for Colleges B, C, D, E, and F, while college A was $75-79 \%$. To divide the sample into contrasting performance groups, a decision was made to standardise the results 
by rating them into 1 (0-49), 2 (50-59), 3(60-69), 4(70-79), and 5 (80100). The procedure was undertaken to carry out a comparative and associative analysis between relatively more or less successful levels of attainment rather than an analyses based on their assessment mark. Ratings were used to identify the way that achievement was operationalised rather than to compare achievement scores across the six PHEI.

To measure students' process skills, six items were modified from the Course Experience Questionnaire by Wilson, Lizzio, and Ramsden (1997). The six items measured process skills relevant to employability and lifelong learning, such as problem solving, analytic skills, teamwork, ability to plan one's own work, written communication, and confidence in tackling new situations. Each of the six items requires the respondents to indicate their agreement on a five-point scale ranging from 1 (strongly disagree) to 5 (strongly agree).

Course satisfaction was measured by an item 'Overall I am satisfied with the quality of this course'. The item was rated on a 5-point Likert scale from 1 'Strongly Disagree', to 5 'Strongly Agree'.

\section{STATISTICAL ANALYSES}

Validation of the modified R-SPQ-2F was conducted with factor and item analysis. A factor analysis was used to examine the internal structure of, first, the 10 items of the motive subscales, and then the 10 items of the strategy subscales. Principal components factor analysis with varimax rotation was used to generate factors for the two data sets. A combination of the scree test and the eigenvalue greater than one rule was used to determine the number of factors to be extracted. As the sample size was more than 300, a slightly more conservative value of 0.45 was chosen for the factor loadings. Internal consistency reliability is estimated by the calculation of coefficient alpha for scores on the four subscales and the two defining approaches to learning.

Internal consistency reliability (Cronbach alpha coefficient) estimates for both the six-item process skills and the PELCQ yielded high reliabilities of 0.79 and 0.83 respectively. 


\section{RESULTS}

\section{Psychometric Properties of the R-SPQ-2F}

Table 3 and Table 4 display the results of the principal components factor analysis for the deep and surface motive and strategy subscales respectively, together with the percentage of variance extracted for each scale. Both sets of results showed clear support for the two factor deep-surface distinction in the approaches to learning construct. The percentage of variance extracted for the motive subscale varies from 21.91 to 22.40 for the two scales, with the total variance accounted for being $44.31 \%$. The percentage of variance extracted for the strategy subscale varies from 18.90 to 20.10 for the two scales, with the total variance accounted for being $41.00 \%$. The factor loadings of the 10 items in the motive subscale and 10 items in the strategy subscale in the instrument support the two-factor deep-surface structure of the modified RSPQ-2F.

Cronbach alpha reliability estimate for the 20 items in the questionnaire was 0.72 , indicating an acceptable degree of overall internal consistency (Watkins \& Mboya, 1997). Scale Reliability of the four subscales (Deep Motive, Deep Strategy, Surface Motive, and Surface Strategy) and of the main scales (Deep and Surface Approach) of the present data is reported in Table 5. Alpha reliability values for the two main scales of Deep Approach (0.80) and Surface Approach (0.77) were fairly high which suggests that each main scale had adequate internal consistency. The alpha values ranged from 0.57 to 0.68 for the four subscales, with a median of 0.67 , which exceeds the threshold of 0.60 set by Nunnally (1978) and Nunnally and Bernstein (1994), as being acceptable reliability for research purposes. In addition, all reliability estimates for the subscales were consistent with those obtained by Biggs, Kember, and Leung (2001) and Leung and Kember (2003) for their Hong Kong samples. In fact, the values for the subscales, Deep Motive and Deep Strategy were generally higher than those reported by Biggs et al. (2001) for the original R-SPQ-2F. 
Table 3. Principal Components Analysis: Motive Subscale

\begin{tabular}{lccc}
\hline Subscale & Item No. & Factor 1 & Factor 2 \\
\hline Deep Motive & 1 & 0.73 & \\
& 5 & 0.59 & \\
& 9 & 0.74 & \\
& 13 & 0.66 & \\
Surface Motive & 17 & 0.56 & 0.66 \\
& 3 & & 0.69 \\
& 7 & & 0.62 \\
& 11 & & 0.71 \\
& 15 & & 21.91 \\
\hline Variance & 19 & 22.40 & \\
\hline
\end{tabular}

Table 4. Principal Components Analysis: Strategy Subscale

\begin{tabular}{lccl}
\hline Subscale & Item No. & Factor 1 & Factor 2 \\
\hline Deep Strategy & 2 & 0.54 & \\
& 6 & 0.66 & \\
& 10 & 0.67 & \\
& 14 & 0.74 & \\
Surface Strategy & 18 & 0.69 & \\
& 4 & & 0.64 \\
& 8 & 0.50 & 0.67 \\
& 12 & & 0.52 \\
\hline Variance & 16 & & 18.90 \\
\hline
\end{tabular}


Table 5. Reliability (Cronbach Alpha Coefficient) Comparisons for the Four Subscales and Two Main Scales

\begin{tabular}{lccc}
\hline & $\begin{array}{c}\text { Present Study } \\
(\mathrm{n}=368)\end{array}$ & $\begin{array}{c}\text { Hong Kong } \\
\text { undergraduate } \\
\text { students } \\
\text { (Biggs et al., 2001) } \\
(\mathrm{n}=495)\end{array}$ & $\begin{array}{c}\text { Hong Kong } \\
\text { undergraduate } \\
\text { students }\end{array}$ \\
& \multicolumn{3}{c}{ 2003) $(\mathrm{n}=402)$} \\
\hline $\begin{array}{l}\text { Subscales } \\
\text { Deep motive }\end{array}$ & 0.68 & 0.62 & 0.60 \\
$\begin{array}{l}\text { Deep strategy } \\
\text { Surface motive }\end{array}$ & 0.68 & 0.63 & 0.62 \\
Surface strategy & 0.66 & 0.72 & 0.72 \\
& 0.57 & 0.57 & 0.59 \\
Main Scales & & & not available \\
Deep Approach & 0.80 & 0.73 & not available \\
Surface Approach & 0.77 & 0.64 & \\
\hline
\end{tabular}

\section{Students' Approaches to Learning and Learning-related Outcomes}

Table 6 provides the results of: (i) the simple correlation analysis of relationships between each learning outcome measure and approach to learning scales, and (ii) the multiple regression analyses of the associations between approaches to learning and each learning-related outcome.

The results of the simple correlation analysis indicated that deep approaches to learning had a positive association with academic attainment, acquisition of process skills, and satisfaction with course. In contrast, surface approaches to learning had negative associations with the three outcome measures. That is, the results indicate that students who adopted deep approaches to learning had higher academic success, better acquisition of process skills, and were generally more satisfied with their course than were students who adopted surface approaches to learning.

In addition, the findings showed a small multiple correlation between students' approaches to learning and students' academic attainment $\left(R^{2}=4 \%\right.$, Effect size $\left.=0.04\right)$, a medium association with the acquisition of process skills $\left(R^{2}=14 \%\right.$, Effect size $=0.16)$, and a medium association with satisfaction with course $\left(R^{2}=10 \%\right.$, Effect Size $\left.=0.11\right)$. The â coeffcients indicated that 
deep approaches to learning were associated with students' higher academic attainment, better acquisition of process skills, and their satisfaction with the course. In contrast, surface approaches to learning were related to students' poorer acquisition of process skills and reduced satisfaction with the course.

Table 6. Simple Correlations and Multiple Regression for Relationships Between Approach to Learning and Learning-Related Outcomes

\begin{tabular}{|c|c|c|c|c|c|c|}
\hline \multirow[b]{2}{*}{$\begin{array}{l}\text { Approach } \\
\text { to Learning }\end{array}$} & \multicolumn{2}{|c|}{$\begin{array}{l}\text { Academic } \\
\text { Attainment }\end{array}$} & \multicolumn{2}{|c|}{$\begin{array}{l}\text { Acquisition of } \\
\text { Process Skills }\end{array}$} & \multicolumn{2}{|c|}{$\begin{array}{c}\text { Satisfaction with } \\
\text { Course }\end{array}$} \\
\hline & $r$ & $\hat{a}$ & $r$ & $\hat{a}$ & $r$ & $\hat{a}$ \\
\hline Deep Approach & $0.16^{* *}$ & $0.15^{* *}$ & $0.32 * *$ & $0.30 * * *$ & * $0.24 * *$ & $0.22 * *$ \\
\hline Surface Approach & $-0.11^{*}$ & -0.10 & $-0.22^{* *}$ & $-0.19 * * *$ & k $-0.18^{* *}$ & $-0.16^{* *}$ \\
\hline Multiple $R$ & & $0.19 * *$ & & $0.37 * * *$ & & $0.28^{* * *}$ \\
\hline$R^{2}$ & & 0.04 & & 0.14 & & 0.10 \\
\hline Effect Size & & $0.04^{\mathrm{a}}$ & & $0.16^{\mathrm{b}}$ & & $0.11^{\mathrm{b}}$ \\
\hline
\end{tabular}

$* \mathrm{p}<0.05 \quad * * \mathrm{p}<0.01 \quad * * * \mathrm{p}<0.001$

Effect size: ${ }^{a}$ small ${ }^{b}$ medium

\section{Students' Background Variables, Approaches to Learning and Learning-Related Outcomes}

Table 7 presents two regression analyses which examine relations among students' background characteristics, approaches to learning, and the learning-related outcomes of students' academic attainment, acquisition of process skills, and satisfaction with the course.

The results indicated that students' choice of academic discipline, high English language competency, and approaches to learning combined to have a medium association with academic attainment scores $\left(R^{2}=19 \%\right.$, Effect size $\left.=0.23\right)$. For acquisition of process skills, high English Language Competency, and approaches to learning combined to be related to a medium amount of variance $\left(R^{2}=42 \%\right.$, Effect size $\left.=0.21\right)$. In addition, high English language competency and approaches to learning combined to have 


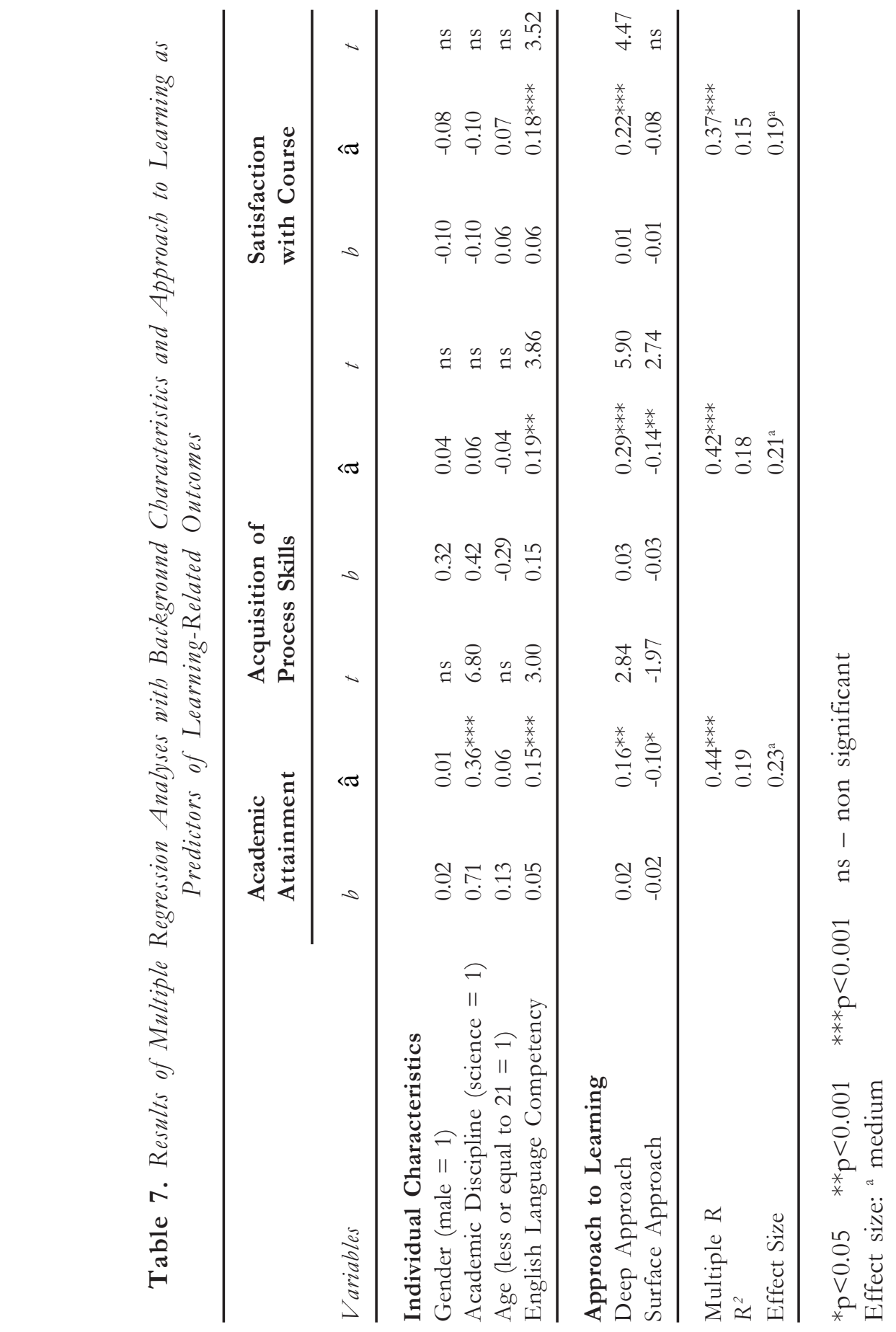


a medium association with students' satisfaction with course scores $\left(R^{2}\right.$ $=37 \%$, Effect Size $=0.19)$. There were no associations between gender, age, and any of the learning-related outcomes, after taking into account the other predictors. Deep approaches to learning were related positively to academic attainment and acquisition of process skills while surface approaches had negative associations with these outcomes.

\section{DISCUSSION AND CONCLUSION}

Through testing, using factor analyses, as well as estimating the internal consistency reliability (Cronbach alpha coefficient), the findings indicated that the Revised Two Factor Study Process Questionnaire (R-SPQ-2F) was a valid and reliable instrument. Hence, the R-SPQ-2F can be used with confidence to evaluate students' approaches to learning from twinning programmes in private higher educational institutions in Malaysia. Although the R-SPQ-2F was revised, re-developed, and validated by Biggs, Kember, and Leung (2001) for lecturers to evaluate tertiary students in Hong Kong, its cross-validation in the present study for students across different course disciplines in twinning programmes in Malaysia demonstrates that this questionnaire is versatile and is suitable for use in a wider range of academic environments requiring little modification and adaptation. Interestingly, the deep and surface mainscales had good á reliability estimates that were higher than Biggs' et al. (2001) original deep and surface mainscales. It appears that it is possible to use the questionnaire in another culture and administer it equally across a number of cultures to produce similar results. In addition, students can use the questionnaire to evaluate their own learning approaches and adjust their approaches to suit their course goals and to improve on the effectiveness of their own learning.

The present investigation produced evidence that students' adoption of deep approaches to learning had significant associations with their academic attainment, acquisition of process skills, and their satisfaction with the course. The results are consistent with investigations which have indicated that students who adopted deep approaches to learning emerged from their course having achieved higher quality learning, including the development of analytic skills, than those who maintained greater reliance on surface approaches 
(Biggs, 1993, Entwisle, 1998). These findings provided further evidence of between-constructs validity by demonstrating that the R-SPQ-2F correlated with other variables, in this case academic attainment scores, acquisition of process skills, and satisfaction with the course.

The results showed that students' choice of academic discipline, high English language competency, and approaches to learning were good predictors of students' learning-related outcomes. Deep approaches to learning were related positively to all learning-related outcomes, while surface approaches had negative relationships with these outcomes. The findings suggest that although deep approaches to learning were preferable in seeking to maximise learning outcomes, students' choice of their academic discipline and possessing high English language proficiency contributed towards their motivation to succeed.

This study made no mention of causality in describing the relationships observed in the study. The study was essentially a correlational one and did not set out to manipulate variables nor was it a longitudinal study due to time constrains. The sample size, although large, only involved second and third year twinning programme students from business, computing, and engineering strands. Nevertheless, the results have provided a greater understanding of twinning programme students in Malaysia.

In conclusion, the major outcomes of the study need to be re-emphasised. The study has provided evidence that the $\mathrm{R}$ SPQ-2F demonstrated highly satisfactory psychometric properties when applied to samples of Malaysian student, in particular twinning programme students. The study adds to prior research by examining the association of approaches to learning and learningrelated outcomes. In addition, the study also adds to the relatively limited number of investigations that have looked at the association among students' background characteristics (such as gender, age, choice of academic discipline, and English language competencies), approaches to learning, and learning-related outcomes. Perhaps it would be interesting to further investigate how students' learning environment contributes to their approaches and their learning outcomes. 


\section{REFERENCES}

Biggs, J.B. (1987). Student approaches to learning and studying. Melbourne: Australian Council for Educational Research.

Biggs, J.B. (1989). Approaches to the enhancement of tertiary teaching. Higher Education Research and Development, 8, 7-25.

Biggs, J.B. (1993). What do inventories of students' learning processes really measure? British Journal of Educational Psychology, 63, 3-19.

Biggs, J.B. (2001). Enhancing learning: a matter of style or approach? In R.J. Sternberg \& L.F. Zhang (Eds), Perspectives on thinking, learning, and cognitive Styles (pp.73-102). Mahwah, NJ: Lawrence Erlbaum Associates.

Biggs, J.B., Kember, D., \& Leung, D.Y.P. (2001). The revised two-factor Study Process Questionnaire: R-SPQ-2F. British Journal of Educational Psychology, 71, 133-149.

Entwistle, N. (1998). Approaches to learning and forms of understanding. In B. Dart, \& G. Boulton-Lewis (Eds), Teaching and learning in higher education (pp.72-101). Victoria, Australia: Australian Council for Educational Research.

Gow, L., \& Kember, D. (1990). Does higher education promote independent learning? Higher Education, 19, 307-322.

Gow, L., Kember, D., \& Chow, R. (1991). The effects of English language ability on approaches to learning. RELC Journal, 22, 49-68.

Harper, G., \& Kember, D. (1986). Approaches to the study of distance education students. British Journal of Educational Technology, 17, 212-221.

Harris, R. (1997). Overseas students in the United Kingdom system. Higher Education, 29, 77-92.

Hattie, J., \& Watkins, D. (1981). Australian and Filipino investigations of the internal structure of Biggs' new Study Process Questionnaire. British Journal of Educational Psychology, 51, 241-244.

Hayes, K., \& Richardson, J.T.E. (1995). Gender, subject and context as determinants of approaches to studying in higher education. Studies in Higher Education, 20, 215-221.

Hui, C. H. \& Triandis, H. C. (1985), Measurement in cross-cultural psychology: a review and comparison of strategies. Journal of Cross-Cultural Psychology, 16, 131-152. 
Johnston, C. (2001). Student perceptions of learning in first year in an economics and commerce faculty. Higher Education Research and Development, 20, 169-184.

Kember, D., \& Leung, D.Y.P. (1998a). Influences upon students' perceptions of workload. Educational Psychology, 18, 293-308. Kember, D., \& Leung, D.Y.P. (1998b). The dimensionality of approaches to learning: an investigation with confirmatory factor analysis on the structure of the SPQ and LPQ. British Journal of Educational Psychology, 68, 395-407.

Kember, D., Charlesworth, M., Davies, H., Mckay, J., \& Stott, V. (1997). Evaluating the effectiveness of educational innovations: using the study process questionnaire to show that meaningful learning occurs. Studies in Educational Evaluation, 23, 141-157.

Knight, P. (1995). Assessment for learning in higher education, London: Kogan Page

Leung, D.Y.P., \& Kember, D. (2003). The relationship between approaches to learning and reflection upon practice. Educational Psychology, 23, 61-71.

Marton, F. (1986). Phenomenography - a research approach to investigating different understanding of reality. Journal of Thought, 21, 28-49.

Marton, F., \& Saljo, R. (1976). On qualitative differences in learning - I outcome and process. British Journal of Educational Psychology, 46, 4-11.

Matthews, B.M. (2003). Life values and approaches to learning: A study of university students from Confucian beritage cultures. $\mathrm{PhD}$ Thesis, The Flinders University of South Australia.

Meyer, J.H.F (1998). A medley of individual differences. In B. Dart \& G. Boulton-Lewis (Eds), Teaching and Learning in Higher Education (pp.42-71). Melbourne: Australian Council for Educational Research.

Miller, CM.L., Finely, J., \& McKinely, D.L. (1990). Learning approaches and motives: males and female differences and implications for learning assistance programs. Journal of College Student Development, 31, 147-154.

Nunnally, J.C. (1978). Psychometric theory. New York: McGraw Hill.

Nunnally, J.C., \& Berstein, I.H. (1994). Psychometric Theory (3 ${ }^{\text {rd }}$ ed). Sydney: McGraw Hill. 
O’Neil, M., \& Child, D. (1984). Biggs' SPQ: a British study of its internal structure. British Journal of Educational Psychology, 54, 228234.

Ramburuth, P. (2000). Cross cultural learning behaviour in higher education: perceptions versus practice. In Ultibase Articles, paper originally presented at the Seventh International Literacy and Education Research Network (LERN) Conference on Learning. 5-9 Jul., RMIT University, Melbourne.

Richardson, J.T.E. (1990). Reliability and replicability of the approaches to studying questionnaire, Studies in Higher Education, 15, 155-168.

Richardson, J.T.E. (1994). Cultural specificity of approaches to studying in higher education: a literature survey. Higher Education, 27, 449-468.

Smith, S.N. (2001). Approaches to study of three Chinese national groups. British Journal of Educational Psychology, 71, 429-441.

Snelgrove, S., \& Slater, J. (2003). Approaches to learning: psychometric testing of a study process questionnaire. Methodological Issues in Nursing Research, 43, 496-505.

Tait, H., \& Entwistle, N. J. (1996). Identifying Students at Risk Through Ineffective Study Strategies, Higher Education 31, 97-116.

Tan, M.C. (1990). Some factors influencing student performance in laboratory experimental work in physiology with implications for curriculum deliberations and instructional design. Higher Education, 19, 473-479.

Trigwell, K., \& Prosser, M. (1991). Improving the quality of student learning: the influence of learning context and student approaches to learning on learning outcomes. Higher Education, 22, 251-266.

Volet, S.E., \& Ang, G. (1998). Culturally mixed groups on international campuses, an opportunity for intercultural learning. Higher Education Research and Development, 17, 5-23.

Volet, S.E., \& Kee, J.P.P. (1993). Studying in Singapore, studying in Australia - a student perspective. Occasional paper 1, Murdoch University Teaching Excellence Committee, Murdoch University, Perth.

Volet, S.E., Renshaw, P.D., \& Tietzel, K. (1994). A short-term longitudinal investigation of cross-cultural differences in study approaches using Biggs' SPQ questionnaire. British Journal of Educational Psychology, 64, 301-318. 
Wan Ali, W.Z. (2000). Memahami pembelajaran. Kuala Lumpur: Utusan Publications \& Distributors Sdn Bhd.

Watkins, D., \& Akande, A. (1992). Assessing the approaches to learning of Nigerian students. Assessment and Evaluation in Higher Education, 17, 11-20.

Watkins, D., \& Hattie, J. (1981). The learning processes of Australian university students: investigations of contextual and personological factors. British Journal of Educational Psychology, 51, 384-393.

Watkins, D., \& Ismail, M. (1994). Is the Asian learner a rote learner? a Malaysian perspective. Contemporary Educational Psychology, 19, 483-488.

Watkins, D., \& Mboya, M. (1997). Assessing the learning processes of black South African students. The Journal of Psychology, 131, 632-640.

Watkins, D., \& Regmi, M. (1990). An investigation of the approach to learning of Nepalese tertiary students. Higher Education, 20, 459-469.

Watkins, D., Regmi, M., \& Astilla, E. (1991). The Asian-learner-as-arote-learner stereotype: myth or reality? Educational Psychology, 11, 21-34.

Wilson, K.L., Lizzio, A., \& Ramsden, P. (1997). The development, validation and application of the Course Experience Questionnaire. Studies in Higher Education, 22, 33-53.

Wilson, K.L., Smart, R.M., \& Watson, R.J. (1996). Gender differences in approaches to learning in first year psychology students. British Journal of Educational Psychology, 66, 5971.

Zakaria, A. (2000). Educational development and reformation in the Malaysian education system: challenges in the new millennium. Journal of Southeast Asian Education, 1, 113133.

Zhang, L.F. (2000). University students' learning approached in three cultures: an investigation of Biggs' 3P Model. The Journal of Psychology, 134, 37-55. 


\section{APPENDIX 1}

The PELCQ

My English Language

competency in:

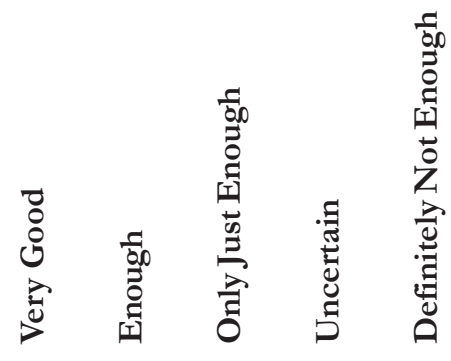

Reading academic text books, materials, handouts, study manuals, printed articles and reading for an essay or assignment. 5 $\begin{array}{llll}4 & 3 & 2 & 1\end{array}$

Writing - assignments, essays, reports (including science, business or laboratory reports), notes during lectures or keeping up with lecturers in terms of note-taking.

Understanding lectures and/or seminars.

$\begin{array}{llll}4 & 3 & 2 & 1\end{array}$

Discussion and Presentation during tutorials, seminars, and in class (e.g. giving instructions, explaining ideas, or getting responses etc.) 5

$\begin{array}{llll}4 & 3 & 2 & 1\end{array}$

Informal everyday conversation with friends and staff (e.g. telling jokes, giving advice, or seeking advice etc).

$\begin{array}{llll}4 & 3 & 2 & 1\end{array}$




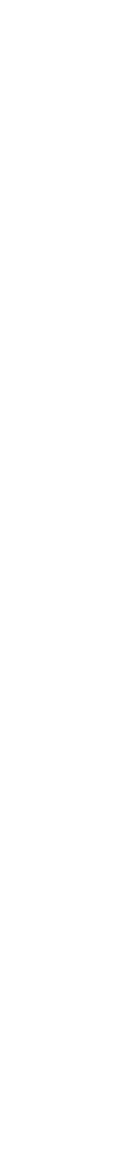

